\title{
AFFIXED TERMS IN COGNITIVE CATEGORIZATION OF THE LEGAL PICTURE OF THE WORLD AND IN LSP TEACHING
}

\begin{abstract}
The interdisciplinary notion picture of the world makes research works devoted to this area of studies challenging from the point of view of finding interconnections between linguistic and extra-linguistic factors in the process of structuring categories of words, including those functioning in terminological systems and subsystems. Legal pictures of the world are specific cultural phenomena that may differ in various countries due to the nationally specific features of law and legal culture development. One of the most complicated problems of representing specific knowledge through linguistic, terminological, signifiers is the problem of linguistic categorization of concepts. The article considers the problem of forming legal categories based on word-building suffixes from the point of view of the development of the legal language 'picture of the world' [reflection of the world] closely associated with its conceptual picture. The conclusion is drawn that commonly used derivational suffixes transform their meanings in accordance with the legal taxonomies, forming the conceptual legal picture of the world. The results of theoretical studies in terminological conceptualization may be used in teaching legal English vocabulary in the form of systematic presentation of term-building patterns expressing certain conceptual categories.

Keywords: world picture, categorization, suffixed terms, derivational meaning, legal terminology, LSP teaching.
\end{abstract}

\section{Linguistic and Legal Pictures of the World}

Modern philosophy defines the term picture of the world as an integral image of the research subject, with its main systematic and structural characteristics generated by fundamental concepts formed in accordance with an original worldview, referring to a definite historical period (Stiopin, 2001: 32). Language picture of the world fulfils two functions: a) signification of the basic elements of the conceptual picture of the world; b) and its explication by the means of linguistic signs (Serebrennikov, 1988: 107). 
Legal language pictures of the world are particular cultural phenomena that may differ from country to country due to the national characteristics of law, legal cultures and language structure.

Acquisition of word pictures is based on knowledge which, as a mental phenomenon, exists in the form of language representation systems, and there are no precise boundaries between linguistic meanings and human experience (Kertész, 2004: 22-23). Linguists believe that meanings expressed by language units form a system of concepts, a uniform worldview, a kind of collective philosophy that is imposed as mandatory upon all language speakers (Maslova, 2001: 65). That is, the linguistic picture of the world is involved in the cognitive process and in interpretation of reality through the prism of language and the speakers' experience acquired with language acquisition, which includes not only learning a huge number of language units, but also the rules of their formation and functioning (Kubriakova, 2004: 64-65).

A linguistic picture of the world, including that of the legal paradigm, can be represented by various parameters (temporal, spatial, quantitative, etc.). However, all these parameters are based on semantics. It is well known that the subject matter of semasiology is not only the study of lexicon, but also of morphology and syntax. "Words ... play such a crucial part in the structure of language that when we speak of semasiology without any qualification, we usually refer to the study of word-meaning proper" (Ginzburg et. al., 1979: 13): this also includes derivational meanings which are a sort of tool for linguistic categorization. The derivative relations of lexical units help us not only to establish correlations between different units of the lexical system, their meanings and semantic patterns, but also understand better the concepts of the "discourse-relevant" type, which are lexical concepts (Hartig, 2016: 71).

Language units that represent the system of concepts in any sphere of knowledge or any practical profession, including the legal profession, constitute terms - words or word-combinations used in those areas and denoting concepts that are specific to those areas. A great number of legal terms in the English language are suffixed derivatives. They are the result of the morphological evolution of terms which reflects a direct link between the morphological and word-building structure of a term and its meaning. Each derivational affix is attached to a specific set of terminological stems and is a means of forming a set of terminological and cognitive categories. 
Affixed Terms in Cognitive Categorization of the Legal Picture...

\section{Categorization in Cognitive Linguistics and Terminological Studies}

Problems of linguistic categorization have always been central in terminological studies. These problems were important in the debate concerning the function and characteristics of terms related to the part-of-speech. O. S. Akhmanova stresses that in European languages, the system of nouns is so well developed, and there are such unlimited possibilities of forming nouns from the stems of verbs and adjectives, that the basic corpus of terms could be represented only by nouns (1969: 11). According to this point of view, verbs are substitutes of codified terms in professional speech, and adjectives are usually parts of terminological word combinations (see e.g. Dokulil, 1962; Danilenko, 1977). Therefore, with regards to terminological categorization, we shall consider terms belonging only to the single part of speech (nouns).

Part-of-speech categorization is subject to further categorization both in common language and in terminologies. Linguistic categorization in all Indo-European languages is exercised mainly by means of word-building suffixes. In linguistics, this kind of categorization is closely connected with linguistic concepts of word-formation category, word-formation type and derivational meaning.

\section{Examples representing the word-formation category}

According to the traditional approach of Russian linguists, the differentiation of word-formation categories is based on the unity of derivational meanings, while the means of their expression may be different. An example of a word-formation category is the category of the performer of an action, formed by adding different suffixes to the verb stems. This category includes nouns with suffixes: -er-teacher, -or-creator, -ant-appellant, etc.

\section{Examples representing the word-formation type}

The word-formation type is a more precise unit of categorization. A word-formation type is a class of derivatives characterized by five wordforming properties: a) the derived words belong to the same part of speech; b) the derivational stems belong to one part of speech; c) the type of word formation is the same (suffixation or prefixation); d) the derivational meaning is identical; e) the affix is the same. E.g., teacher, speaker, thinker, listener, etc.

T. L. Kandelaki, using onomasiology approach to the study of the processes of terminological nomination, arrived at the conclusion that termino- 
logical categories (extremely numerous semantic groups of terms) are the most important phenomena in structuring of the system of terminological vocabulary. In technical terminologies, she found categories of processes, qualities, objects, values, measure units, sciences and their branches, professions, etc. (1979: 9).

Later the problem of categorization has become one of the most important ones in cognitive linguistics, because categorization is the main way of representing the perceived world as orderly and organized, of systematizing it and observing the similarity between some phenomena and their oppositions (Kubriakova, 1994). The problem of linguistic categorization is based on onomasiology approach to the analysis of language phenomena, which presupposes the point of view of the speaker been taken into consideration, who looks for linguistic forms to express some extra-linguistic content, while using the units of language in his or her speech.

Thus, the theory of terminological nomination, as well as the theory of nomination in general, developed into the framework of cognitive linguistics and finding correlation of linguistic forms with their cognitive peers, i.e. as the process and the result of objectification of the reality.

Sometimes derivational meanings were studied in terms of logical opponents (the subject, the object, the whole and the part, etc.) (Glumov, 1989). More rarely, linguists singled out specified derivational meanings. E.g., L. A. Dines found that even a specific categorical meaning might be expressed by a terminological morphem (suffix). As an example, she considered the formation of such terminological derivational and categorical meaning in medical terminology as "inflammation" with the help of the terminological suffix -ITIS: pericarditis, myocarditis, hepatitis, vasculitis, nephritis, etc. (Dines, 1985). In the German terminology of botany A. Yu. Belova (1997) revealed the transformation of the common language derivational meanings formed with the help of the suffixes -CHEN, -LEIN, -LING into a uniform terminological meaning "plant" (Engelsblüchen, Goldröslein, Bitterling).

In any case, the authors stressed that ordinary derivational meanings are always subject to semantic transformations when belonging to specific classifications of an area of knowledge.

\section{Material and Methods}

The material of the study in this article is represented by 1294 English suffixed legal terms (nouns) selected from various terminological dictionaries of law. 
Analyzing the word-formation specifics of legal terms we shall follow the rules of the derivational analyses presented above, as opposed to the morphological analysis of the word structure.

According to studies on modern word-formation in the English language, researchers specify a different number of noun-forming suffixes. R. G. Zyatkovskaya (1971) finds 60 of them. Our material shows that in legal terminology just 20 noun-forming suffixes classify 23 derivational meanings. This reduction of the suffix system of the English language in legal terminology is explained by the fact that the system of legal concepts determines the range of suffixes used for coining the words of common discourse. One suffix may convey several derivational meanings. E.g., -er lawyer, binder. These facts are also important for teaching and studying legalese.

The process of transformation of common derivational meanings into terminological ones is based on a logical analysis of how legal taxonomy influences the unification of terms, with heterogeneous suffixes into one cognitive legal category.

\section{The System of Suffixes Used for Coining English Legal Terms and Other Specific Features of Term-Formation}

Derivational suffixes are not combined as freely and regularly as functional suffixes $(-e s, e d)$. The rules of their combination in legal terminology are determined by linguistic and extra-linguistic factors. The linguistic factor is the influence of the language system, and the extra-linguistic factor is the influence of the system of concepts deliberately incorporated into the legal fragment of the linguistic world picture by lawmakers.

In English legal terminology, nouns derived from verbal stems are the most productive ( $80.1 \%$ of terms). This clearly manifests the necessity to designate actions and their results with the help of nouns. $70 \%$ of legal terms coined from verbal stems with 8 suffixes and their variants (-AGE, -AL, ANCT/-ENCE, -ING, -ION/-TION/-ATION/-SION, -MENT, -Y, -URE) objectify various lawful or criminal actions (to freight-freightage, to dismiss - dismissal, to accept - acceptance, to vote - voting, to vindicate - vindication, to disfranchise - disfranchisement, to inquire - inquiry, to foreclose - foreclosure). The second highest productive set of suffixes (-ANT, -EE, ER/OR) objectify the category of "doer of an action" (24.4\% terms): to declare - declarant, to absent - absentee, to murder - murderer. Other affixed terms have derivational meanings "addressee of an action" (-EE: to offer - 
offeree) and "thing that originated as a result of an action" (-ER: to bind binder).

Derivatives formed with the help of adjectival stems and suffixes -ITY, NESS, -ISM possess less diverse derivational meanings as compared to those derived from verbs. Their derivational meaning is a "phenomenon characterized by a feature named by the motivating stem" (authentic - authenticity, stateless - statelessness, constitutional - constitutionalism).

Suffixed terms derived from nouns with the suffixes -ARY, -ACY, -AGE, -ER, -DOM, -HOOD, -SHIP, $-\mathrm{Y}$ are, from the point of view of derivational meaning, more diverse. They form terms with three such meanings: a) "a person characterized by the relation to what is signified by the motivating stem" (commission - commissioner, law-lawyer), b) "action associated with a person who is signified by the motivating stem" (pirate - piracy, vagabond - vagabondage, robber - robbery), c) "state of a person signified by the motivating stem" (official - officialdom, orphan - orphanhood, citizen citizenship).

Thus, one may say that all the above-mentioned derivational meanings are typical of the conceptual system of English legal terminology.

Suffixes in legal terminology, like those in common word-formation process, may be productive (-ER, -ION, etc.) and non-productive (-DOM), monosemantic (-ION: violation, resolution - "action and its result") and polysemantic (-ER: lawyer - "profession of a person", borrower, forger "doer of an action", binder - "thing that originated as a result of an action"). Some suffixes may be synonymous (-DOM, -HOOD, -SHIP: orphandom, orphanhood, orphanship).

Many suffixes are not used for coining legal terms, because their derivational meanings do not match legal categories for various reasons. Some of them belong to other specialized areas, e.g., medicine (-ITIS: it bronchitis, -OSIS: salmonellosis), chemistry (-IUM: Curium, Californium) and other sciences (-GRAPHY: orthography, oscillography, ethnography), etc.

The noun suffix -FUL (handful, pocketful, spoonful), which is very productive in modern English, is not used in legal term-formation, because its derivational meaning ("an amount of something fitting some volume or container") does not correspond to any legal category.

Other suffixes are not used in legal terminology because their meanings are not of denotational, but of connotation origin (-ETTE: dinette, kitchenette, -IE/Y: auntie, girlie, -LING: duckling, -LET: booklet, branchlet).

Some noun-forming suffixes do not form the terms proper, but they are necessary for coining speech substitutes of codified terms, which are necessary elements of oral legal discourse. E.g., murderer is a codified le- 
gal term; the word murderess is a speech substitute for the codified term murderer.

Some suffixes are specific to the legal field. E.g., the suffix -EE (adoptee) and the semi-suffix-CIDE (infanticide, homicide) originated for coining legal terms and only then did they begin to be used for denoting non-legal notions (trainee, insecticide).

\section{Transformation of Derivation Meaning in Legal Terminology}

The need for the introduction of the category of term-forming derivational meanings is especially important for legal terminology because:

a) The majority of the suffixes used to coin new legal terms are also used for coining commonly used words;

b) It is possible to single out specific terminological derivation meanings in legal terminology.

Common language derivational meanings in terminologies tend towards greater unification. For example, this specific characterristics of terminological derivational meanings may be observed in the subsystem of terms denoting the legal category of a "person". In legal terminology, this taxonomy unites not only natural persons (human beings) but also juridical (artificial) persons or legal personalities (corporations, associations, etc.). E.g.:

\section{"Person}

n. 1) a human being. 2) a corporation treated as having the rights and obligations of a person. Counties and cities can be treated as a person in the same manner as a corporation. However, corporations, counties and cities cannot have the emotions of humans such as malice, and therefore are not liable for punitive damages unless there is a statute authorizing the award of punitive damages" (Legal dictionary).

Because of this, such derivational meanings of commonly used words as "doer of an action" (owner), "addressee of an action" (offeree), "person characterized by the relation to the object named by the underlying stem" (lawyer), "organization" (partnership) form one legal (cognitive) and derivational category - "person".

Such derivational meanings, as "action and its result", "state or quality named by the motivating stem" in legal terminology express the legal category of "fact". E.g.:

\section{"What is a FACT?}

A thing done; an action performed or an Incident transpiring; an event or circumstance; an actual occurrence... A fact is either a state of things, 
that is, an existence, or a motion, that is, an event... A circumstance, event or occurrence as it actually takes or took place; a physical object or appearance, as it actually exists or existed. An actual and absolute reality, as distinguished from mere supposition or opinion; a truth, as distinguished from fiction or error" (Black's law dictionary).

Thus, the terms with suffixes -TION (appellation), -AL (withdrawal), -ENCE (fraudulence), -Y (burglary) -ITY (probity) may be considered as those possessing a uniform legal terminological meaning, though their derivational meanings in the common discourse are different.

The meanings of the suffixed legal terms, besides lexical meaning, include the following three types of meanings: a) that of a grammatical category, b) one that identifies the legal specificity of category classification, c) common use derivational meaning.

The latter type of meaning is still very important for legal terminology, because it often retains in it the classification value. These three meanings form a hierarchical sequence: Grammatical (categorical) meaning ("thingness") $\rightarrow$ Generic terminological meaning (e.g., "personality") $\rightarrow$ Specific terminological meaning (e.g., "corporation") $\rightarrow$ Derivational meaning identifying further classifications of legal categories, which sometimes equals commonsense derivational meaning (e.g., "doer of an action", "addressee of an action").

It should be noted, however, that the formation of terminological derivational meanings of suffixed terms does not cover the entire system of concepts in legal taxonomy. Thus, the terminological meaning of an "event" is absent in the system of the suffixed legal terms, since the nominative units of this subsystem are represented mainly by root terms and compound nouns borrowed from the common use vocabulary (fire, earthquake, death, etc.).

Fixation of monosemantic terminological derivational meanings with the help of the suffixes borrowed from the sphere of common usage is probably impossible; firstly, because of the influence of the language system, in which suffixes are often polysemantic; and secondly, because in the terminological systems the notions are often classified conditionally; and the basis of classification may change as a result of the extra-linguistic influence (e.g., the legality or illegality of same sex marriages and active euthanasia). Only terminological elements (semi-suffixes) borrowed from classical languages (Greek or Latin) can be monosemantic. E.g., cide $<$ Lat. caedes (murder): prolicide $<$ proles (prolis) (offspring) + caedes (murder of child, syn. infanticide), patricide $<$ pater (patris) (father) + caedes (murder of father). 
Affixed Terms in Cognitive Categorization of the Legal Picture...

\section{Terminological Word Building in LSP Teaching}

With the help of word-building analysis, one can not only acquire linguistic skills and habits for structural analysis of terms and learn about characteristic features of a foreign legal picture of the world, but also find some cultural specifics of categorization in terminologies of two or more languages using contrastive analysis.

For example, in English legal terminology the suffix -EE has two derivational meanings: 1) "addressee of an action" (legatee, offeree, transferee); 2) "doer of an action" (absentee). In Russian legal terminology the suffix AT, corresponding in its meaning to the English -EE, is not used for coining terms with the meaning "doer of an action". Besides, the suffix -AT is used relatively rarely (индоссат) in, Russian legal terminology, and, the English suffix -EE is very productive. The necessity of denoting the addressees of actions in Russian is compensated by means of coining terminological word combinations (offeree - aдpecam oфepmbl).

The tasks of word-building training exercises in legal English teaching may be varied, e.g.:

a) Form legal terms using the following suffixes,

b) Analyze the structure of the terms from the point of view of wordformation rules,

c) Formulate the derivational meaning of the following suffixed terms,

d) Group the terms listed below according to similarities of their derivational meanings,

e) Group the following terms according to legal categories they stand for,

f) Compare the derived English terms with those in the native language from the point of view of form, distribution, meaning and classification. The latter aspect of contrastive analysis for teaching purposes was developed by R. Lado and is important in the cross-cultural approach to teaching foreign languages. According to R. Lado, teaching the rules of wordformation may be based on three types of contrastive bilingual analysis of: 1) form, 2) meaning, 3) distribution of terminological elements in the structure of the language unit (1999: 76). For terminological units I suggest that we add the forth component - legal classification.

Here are just a few examples of such an analysis of English and Russian terms:

1. Same form, same distribution, same meaning, and same classification: a) form (constitutionalism - конституционализм), b) distribution (the stem of the noun + international suffix-ISM, -ИЗM), c) meaning (constitutional authority), d) classification (legal principles). 
2. Different form, same distribution, same meaning, and same classification: a) form (owner - владелеu), b) distribution (the stem of the verb + suffix), c) meaning (a person who owns property), d) classification (person).

3. Different form, different distribution, same meaning, and same classification: a) form (offeree - adpecam oøepmbl), b) (a suffixed term vs. word combination), c) meaning (a person or an organization for whom an offer is extended), d) classification (person).

4. Different form, different distribution, different meaning, same classification: a) form (infanticide - убийство матерью новорожденного ребенка), b) distribution (a suffixed term vs. word combination), c) meaning (the criminal is not specified vs. the criminal is specified), d) classification (fact).

We may find more similarities and dissimilarities when comparing the terms of different structure (non-derived, prefixed and word combinations). Similarities and dissimilarities revealed using such analysis show the student of law the cultural context of the term (both linguistic and extra-linguistic). Awareness by students of the fact that the system of suffixes used for coining legal terms is more restricted as compared to the system of suffixes used in common word building could help them master terminological wordformation rules and patterns more efficiently.

\section{Conclusions}

In the article, I attempted to demonstrate that derivation and categorization approaches to the analysis of legal terms is important both from theoretical and practical points of view.

One of the main aspects of the general theory of terms and the theory of legal terminology is the study of systematic and semantic properties of terms, with differences not only between the common language lexical system and the system of legal terms, but also between suffixed terminological derivatives, which play an important role in linguistic structuring of legal reality.

The cognitive approach (the study of terminological categorization) coupled with derivational analyses of legal terms in different languages, is helpful for developing specialized legal dictionaries for learners of legalese:

a) Ideographic dictionaries in which words close in meaning are grouped together, taking into consideration their paradigmatic relations; such dictionaries are helpful in mastering legal classifications and sub-systems of terms; 
b) Reverse dictionaries that help the learners systematize linguistic knowledge in the sphere of word formation,

c) Derivation and semantic dictionaries based on both approaches to the description of language units,

d) Activators that help students learn legal terms using the whole complex of linguistic and extra-linguistic information presented in the dictionary. The practical importance of contrastive categorization analysis of legal terms functioning in two or more languages and legal cultures in a classroom helps the students better understand general and the specific features of the systems of legal notions expressed by terms of various national legal cultures. In particular, such analysis is helpful in mastering the following terminological aspects:

a) The system of word-formation tools used for coining legal terms,

b) The rules of distribution of elements of a term in the English language and in the mother tongue,

c) The system of legal derivational meanings provided by word-building types united in categories according to the part-of-speech belonging of stems, the formal and the semantic identity of a suffix,

d) Manifestations of polysemy and synonymy in the sphere of wordbuilding suffixes used for coining terms,

e) Legal categories,

f) Cultural similarities and dissimilarities between the systems of terms, their meanings and the legal categories they denote,

g) Specific features of the legal language pictures of the world formed by the systems of terminological units.

Teaching materials must include subsections of practical word-building tasks, accompanied by theoretical linguistic and extra-linguistic information as an analytical component of teaching. The extra-linguistic component in teaching legal English represents specifics of foreign legal culture, illustrated both by language units (terms) and terminological (word-building) elements forming such terms and referring to the legal system of one English speaking country only, or to several of them. Sure enough, contrastive analysis of legal terminology of the mother tongue with foreign ones in the latter case becomes more labour-intensive, but it is also more profound. The sphere of legal terms and notions is vast; therefore, the task of the instructor is to decide which fragments of the legal picture of the world must become topical objects of teaching at definite levels of learning legalese. This approach is especially important in teaching legal translators and lawyer-linguists.

Every linguistic and extra-linguistic aspect of instruction demands a pedagogical background. It is well known that there are no perfect methods 
of teaching foreign languages; the best result is achieved when various methods are combined to meet the requirements of the whole scope of general and specific pedagogical principles. The approach described in this paper meets the requirements of the following principles of pedagogy: systematic teaching, functionality, novelty, interrelated learning of foreign culture, modeling the content of foreign culture.

\section{R E F E R E N C E S}

Akhmanova, O. S. 1969. Slovar' lingvisticheskikh terminov [Dictionary of linguistic terms]. Moskva: Sovetskaya entsiklopediya.

Belova, A. Yu. 1997. 'Diakhronicheskiy aspekt v razvitii terminosistem' ['Diachronic aspect of terminological system development']. Yazyk i obshchestvo [Language and Society]. 11: 33-36.

Black's law dictionary. Retrieved May, 2017 from http://thelawdictionary.org/fact.

Danilenko, V. P. 1977. Russkaya terminologiya: Opyt lingvisticheskogo opisaniya [Russian terminology: an experience of linguistic description]. Moskva: Nauka.

Dines, L. A. 1985. 'Mesto sostavnykh terminov v chastnykh terminologicheskikh sistemakh' ['The place of compound terms in branches of terminological systems'] in M. B. Borissova (ed.) Aktual'nye problemy sovremennoy filologii [Topical problems of modern philology], 27-36.

Dokulil, M. 1962. Tvořeni slov v češtině. I. Teorie odvozovani slov. Praha: Academia.

Ginzburg, R. S., Khidekel, S. S., Knyazeva, G. Y., \& Sankin, A. A. 1979. A Course in Modern English Lexicology. Moskva: Vysšaja škola.

Glumov, V. I. 1989. 'Modelirovanie vneshney i vnutrenney struktur sostavnykh vychislitel'nykh terminov' ['Modelling of meaning and form of computer engineering complex terms'] in B. N. Golovin (ed.), Terminy v nauchnoy $i$ uchebnoy literature [Terms in Scientific Literature and Textbooks], 81-90.

Hartig, A. J. 2016. 'Intersections between law and language. Disciplinary concepts in second language legal literacy.' Studies in Logic, Grammar and Rhetoric. 45 (58): 69-86. DOI: 10.1515/slgr-2016-0016.

Kandelaki, T. L. 1997. Semantika i motivirovannost' terminov [Semantics and Motivation of Terms]. Moskva: Nauka.

Kertész, A. 2004. Cognitive Semantics $\mathcal{E}$ Scientific Knowledge. Case studies in the cognitive science of science. J. Amsterdam, Philadelphia: Benjamins Publishing Co.

Kubriakova, E. S. 1994. 'Nachal'nye etapy stanovleniya kognitivizma: lingvistika psikhologiya - kognitivnaya nauka' ['The initial stages of cognitive science formation: linguistics - psychology - cognitive science']. Voprosy yazykoznaniya [Problems of Linguistics]. 4: 34-47. 
Affixed Terms in Cognitive Categorization of the Legal Picture...

Kubriakova, E. S. 2004. Yazyk i znanie: Na puti polucheniya znaniy o yazyke: Chasti rechi s kognitivnoy tochki zreniya. Rol' yazyka v poznanii mira [Language and Consciousness: On the way to knowledge acquisition: Parts of speech from the cognitive point of view]. Moskva: Yazyki russkoy kul'tury.

Lado, R. 1999. Linguistics across Culture: Applied Linguistics for Language Teachers. Ann Arbor: The University of Michigan Press. (Original work published in 1957).

Legal dictionary. Retrieved May, 2017 from http://dictionary.law.com/Default.aspx ?selected $=1516$.

Serebrennikov, B.A. 1988. Rol' chelovecheskogo faktora v yazyke: Yazyk i kartina mira [The role of human factor in language: Language and picture of the world]. Moskva: Nauka.

Stiopin, V. S. 2001. Novaya filosofskaya entsiklopediya [New Philosophic Encyclopedia]. Moskva: Mysl'.

Zyatkovskaya, R.G. 1971. Suffiksal'naya sistema sovremennogo angliyskogo yazyka [The Suffix System of Modern English Language]. Moskva: Vysšaja škola. 